\title{
Screening Study
}

National Cancer Institute

\section{Source}

National Cancer Institute. Screening Study. NCI Thesaurus. Code C71485.

Clinical studies testing the efficacy of devices, techniques, procedures, or tests for the purpose of detecting the presence of disease, usually before there are any symptoms. 